\title{
Scientific Paradigms, Entrepreneurial Opportunities and Cycles in Economic Growth
}

Mark Sanders

\begin{abstract}
In this paper I present a model of economic growth that combines insights from endogenous growth theory, the field of entrepreneurship research and the philosophy and economics of science. The model is built on three relatively standard assumptions and a Kuhnian approach to scientific knowledge accumulation. I assume that innovation generates economic growth, that opportunity driven entrepreneurship is an important source of innovation, that entrepreneurial opportunities increasingly arise out of scientific knowledge creation and that science follows Kuhnian paradigm shifting dynamics. The model then generates opportunity driven cycles in entrepreneurial activity that in turn cause waves of innovation and cycles in economic growth. This result is highly relevant and fills a gap in all three literatures as 'traditional' endogenous growth models typically generate constant growth rates in the steady state, entrepreneurship research keeps the origin of entrepreneurial opportunity exogenous and the literatures on the philosophy and economics of science ignore the important downstream economic implications of the non-profit driven institutional framework that governs scientific knowledge accumulation. This paper contributes by identifying scientific institutions and entrepreneurial activity as prerequisites for economic growth and it offers a tentative explanation for the rise and fall in the levels of scientific, entrepreneurial and economic activity over the Kondratieff-cycle.
\end{abstract}

KEYWORDS: endogenous growth theory, entrepreneurship, paradigms, scientific institutions.

JEL-CLASSIFICATIONS: E32, L26, M13, O11, O31, O41.

Final version accepted on November 2006.

Mark Sanders

Tjalling Koopmans Institute

Utrecht University

Utrecht, Netherlands

Evolutionary Economics Group

Max Planck Institute of Economics

Kahlaische Strasse 10, 07745, Jena, Germany

E-mail:m.sanders@econ.uu.nl

\section{Introduction}

Politicians and academics readily acknowledge the importance of both science and a healthy and vibrant entrepreneurial sector for generating economic growth. The former is seen as the source of new knowledge whereas the latter is the channel through which that knowledge enters the economy. The European Commission's recent Green Paper on Entrepreneurship (EU, 2003) and accompanying Action Plan (EU, 2004) illustrate that view. The famous Bayh-Dole Act of 1980 in the US also exemplifies the importance politicians attach to the science and entrepreneurship nexus.

The link between scientific discovery and economic growth on the one hand has a long history in the economic literature. ${ }^{1}$ Theoretical work and empirical evidence, linking entrepreneurship to innovation and growth on the other hand is also accumulating rapidly (e.g. Cantillion, 1755; Schumpeter, 1934 and recently Acs et al., 2004, 2006; Karlsson, et al., 2004; Audretsch and Thurik, 2002). Making the connection between economic performance and science through entrepreneurial activity, however, is not that self-evident in the literature. In fact the relevance of entrepreneurs for economic growth and of science as a source for entrepreneurial opportunities has only recently been rediscovered. ${ }^{2}$ In the academic literature entrepreneurship, science and economic growth are still largely studied in isolation.

Entrepreneurship research, the philosophy and economics of science and modern growth theory, however, have quite a lot to learn from each other. In this paper I will present a model that connects these literatures by taking some 
key insights away from each. I assume (with modern growth theory) that innovation, the commercialization of new knowledge, creates growth. Then (with entrepreneurship research) I assume that entrepreneurs commercialize the opportunities that new knowledge creation presents, taking away the rents and profits as their reward. And finally (with the philosophy and economics of science) that knowledge creation follows a reputation driven, cyclical paradigm shifting dynamic as described first by Kuhn (1971). By taking a Kuhnian approach to scientific knowledge creation and linking scientific knowledge creation to entrepreneurial opportunity recognition and innovation, the model endogenizes the aggregate level of entrepreneurial activity and generates opportunity driven cycles in entrepreneurial activity and economic growth. In doing so it contributes to endogenous growth theory by connecting it to the wealth of insights from entrepreneurship research, to the field of entrepreneurship by uncovering one important source of opportunity and to the literature on the evolution of science by making its relevance for the process of economic growth explicit. The main contribution of bringing these literatures together is the fact that the total will turn out to be larger than the sum of its parts.

I first present a short survey of the relevant literatures, then spend some time on introducing and justifying my Kuhnian approach to science. Then I present and analyze the model, which borrows heavily from endogenous growth theory and introduces both entrepreneurs and scientists.

\section{Entrepreneurship and the theory of economic growth}

The field of Entrepreneurship research was defined by Shane and Venkataraman (2000) to study: "how, by whom and with what consequences opportunities to produce future goods and services are discovered, evaluated and exploited". 3 This definition explicitly focuses on the chain of events that follows the initial emergence of an opportunity and ignores how such opportunities come to exist. Entrepreneurship research thus takes the emergence of such commercial opportunities largely as given. ${ }^{4}$ Still the nature of the opportunity under investigation is so fundamental that the literature on entrepreneurship has frequently been classified (e.g Wennekers and Thurik, 1999; Karlsson et al., 2004; Audretsch and Keilbach, 2005), according to the type of opportunity under investigation. The opportunities considered range from Kirznerian (1973) arbitrage opportunities that involve no innovation and move the economy towards the production possibilities frontier to the Schumpetarian (1934) commercial introduction of radically new inventions, that move that frontier out. ${ }^{5}$ This broad scope has allowed entrepreneurship research to span a wide variety of issues, that in addition has been addressed from many disciplines ranging from innovation management to cognitive psychology.

Most of that literature aims at identifying the (idiosyncratic) factors that explain the willingness and ability of (individual) entrepreneurs to recognize and successfully exploit the opportunities that come along. Such factors go a long way in explaining the individual, regional and international differences in entrepreneurial activity. It is beyond the scope and purpose of this paper to give a complete overview of what may motivate and enable or prevent an entrepreneur to act on an opportunity. ${ }^{6}$ At this point I observe from this literature that the creation of new ideas and more precisely, commercial opportunities is usually treated as an exogenous supply push factor in the decision to become an entrepreneur and consequently in determining the aggregate level of entrepreneurial activity.

Probably for that reason modern growth literature largely abstracts from the entrepreneur and has generally ignored entrepreneurship research. Despite models that explicitly acknowledge their Schumpeterian roots (Aghion and Howitt, 1992; Segerstrom et al., 1990), the entrepreneurial function usually coincides with that of the knowledge creator. The implicit justification is that separating them has little to offer when the focus is at the macro-level. At the aggregate level idiosyncratic factors average out and as an average entrepreneur recognizes an average number of opportunities and given his average propensity, ability and talent to pursue 
that opportunity, such a separate agent merely creates a flow of successful innovations that is largely determined by the arrival rate of opportunities.

Therefore entrepreneurship research cannot help to explain the Solow (1957)-residual that motivated growth theory for the past half a century. Growth theory rather turns directly to the origin of the knowledge that underlies commercial opportunities. Arrow (1962) for example linked knowledge accumulation and opportunity creation as a positive externality to the production process through learning-by-doing. With the contributions of Romer (1990), Grossman and Helpman (1991) and Aghion and Howitt (1992) knowledge was privatized, the externality partially internalized and the creation of commercial opportunities was modeled as the purpose of an economic activity in itself. ${ }^{7}$

In general these models and the avalanche of papers that followed (see for good surveys, Aghion and Howitt, 1998; Barro and Sala-IMartin, 2004; Jones, 2006), implicitly assume that commercialization is trivial and treat the decision to create and exploit knowledge as a single rational decision that involves weighing expected future profits against current costs of creating knowledge in terms of some dedicated R\&D inputs. But that shortcut is only justified when collapsing these decisions into one does not change the results in a qualitative way. The model below will show that it does.

If commercialization is not assumed to be trivial and the entrepreneur captures the rents of commercialization, these rents are a reward for bearing the risk and making the effort to turn an opportunity into a product and organizing production. But if the entrepreneur does not engage in opportunity creation, then these rents cannot provide the incentive for knowledge creation as they do in endogenous growth models. Who then generates the knowledge and for what reason? To address that question let us take a step back and consider knowledge itself.

\section{The origins of knowledge}

Broadly speaking knowledge is generated in two ways. Research in laboratories and universities might be the first way that springs to the modern mind but in fact learning by doing (Arrow, 1962) has been the dominant source of knowledge accumulation over most of human history and remains incredibly important even today. One can thus actively pursue knowledge or come across it. Arguably these activities can also generate two types of knowledge. These I will classify broadly as fundamental and instrumental knowledge respectively. ${ }^{8}$ Consider for example fire. The instrumental knowledge of fire allowed cavemen to use it to warm themselves and cook their food. Also they learned by doing that fire needed to be fed with combustibles and that blowing into the flames increased the generated heat. Over the centuries that instrumental knowledge has expanded and many commercial opportunities and new technologies emerged. Bread, metallurgy and blast furnaces are but a few examples that were developed mainly on the instrumental knowledge of fire alone.

The fundamental knowledge of fire, despite efforts by for example the Greek philosophers in Antiquity and a few scattered scholars in the Middle-Ages, hardly developed before the 19th century. The difference is between knowing and understanding fire, between knowing what works and why it works. Learning by doing is obviously very effective in generating instrumental knowledge and only generates fundamental understanding by accident. Pure science on the other hand is entirely focused on generating fundamental knowledge, but has no clear direct application in mind. ${ }^{9}$

Therefore fundamental knowledge in general is a richer source of opportunity as it is understood in this paper. Scientists put very little effort in finding commercial applications (over and beyond the development of scientific instruments) and science may thus be said to produce new commercial opportunities as an unintended side-product. ${ }^{10}$

Modern endogenous growth models focus on the non-rivalry of knowledge and the economics of scale that therefore exist at the aggregate level. As instrumental knowledge is often tacit whereas scientific knowledge is always published (see below) one would expect that the knowledge they refer to is fundamental. But the process they model resembles gradual and accumulative learning more than it captures the process of 
fundamental knowledge evolution itself. This is increasingly important as science and fundamental knowledge are quickly replacing learning by doing and instrumental knowledge as the main source of opportunity for commercial innovation. If anything this trend has gained momentum over the 20 th century. ${ }^{11}$

The increasing importance of science for growth is not only derived from the direct creation of unexploited opportunities. A lot of the evidence on patent citations (e.g. Grilliches, 1979, 1984, 1992; Jaffe, 1986; Jaffe and Trajtenberg, 2002) shows that commercial opportunities are often clever re-combinations of existing and new knowledge. Arrowian learning-by-doing and Romerian commercial R\&D are particularly likely to generate such recombinations, accidentally and intentionally, respectively. ${ }^{12}$ So to the extent that learning-bydoing and commercial R\&D generate the commercial opportunities that the entrepreneurs can act upon, their models capture much of what we measure as economic growth. ${ }^{13}$

However, as Olsson $(2000,2005)$ shows, recombinatory knowledge expansion faces strong diminishing returns without the occasional introduction of genuinely new knowledge. Such genuinely new knowledge cannot be considered "manna from heaven" or a mere side product of normal commercial activity, lest we return to the Solowian world, where ultimately growth is exogenous. Commercially driven $R \& D$ as in Romer is also unlikely to generate a lot of that genuinely new knowledge as the returns are highly uncertain and very hard to appropriate. So more important than the direct commercial opportunities that are left unexploited by scientists, the fundamental knowledge they create has the potential to open up new area's and paths for instrumental knowledge creation to proceed without running into diminishing returns.

The vast literature on technological paradigms (Nelson and Winter, 1977; Dosi, 1982) and General Purpose Technologies (Bresnahan and Trajtenberg, 1995) presents a more historical perspective on economic development that stresses the importance of these occasional knowledge breakthroughs that set off a new period of high entrepreneurial activity and consequently a wave of incremental, re-combinatory product and process innovations. To capture such dynamics in a growth model I introduce a separate sector dedicated to producing new fundamental knowledge: basic science. ${ }^{14}$

\section{Science and scientists}

The critical consideration to be made in this light is that scientists are a different breed of economic agents altogether. Quite a large literature in the philosophy and economics of science has evolved on that topic, although to my knowledge it has not been brought to bare on the issues of economic growth or entrepreneurship. ${ }^{15}$ As fundamental knowledge creation takes place in what we may label the scientific community, the incentives and constraints as well as its institutions require further discussion before the endogenous emergence and subsequent commercialization of opportunity itself can be modeled. By now it is clear that traditional and modern growth theory only offers a few useful starting points in this respect. To dig deeper we need to consider perhaps less orthodox strands of literature that are relevant here.

In this section I will discuss insights from Thomas Kuhn and link his seminal essay on scientific evolution to the literature on the economics of science that explicitly addresses the incentives and constraints that motivate scientists. ${ }^{16}$ We will see that these differ quite significantly from those in commercial R\&D. As a consequence fundamental knowledge evolution follows a very different pattern than the smooth steady state that commercial innovation driven new growth models predict.

The motivation for choosing Kuhn's 'model' is threefold. Although published in the early 70 s this monograph still in many ways represents the state of the art in thinking about science and scientific activity. More elaborate, more complicated and more detailed theories of scientific knowledge creation have been published since but none have overturned any of Kuhn's key results or challenged his detailed account of the institutional setting that produces them. ${ }^{17}$ Also, Kuhn is part of most academic training and therefore requires 
refreshing rather than fully developing his narrative, saving me and the reader a lot of time. Finally, and that is not a small advantage over alternative more modern theories of science, Kuhn's theory has been shown to be internally and dynamically consistent and logically sound by Sterman (1982) and Sterman and Wittenberg (1999), who reproduced Kuhn's key predictions in a simulation model. As Kuhn's model is sufficiently rich but not too complex, is almost common knowledge and has been shown to be suitable for my purpose, I will restrict myself to his theory.

Kuhn first argues that scientific knowledge, a constellation of facts, theories and methods, evolves historically and not, as textbooks would suggest, accumulate in a linear fashion from ignorance to full knowledge of the truth. A scientific discipline is born with the emergence of its first paradigm; a scientific achievement or insight that for a period of time is broadly shared among those engaged in scientific research. Once a paradigm has emerged the discipline will never be without one, although it typically does not remain the same over time. It is the existence of a paradigm that makes a discipline "scientific".

The function of a paradigm is not to embody absolute truth or even necessarily bring the discipline closer to the truth but merely to guide further scientific activity. Scientists, however, have to believe in the truth of the paradigm to be able to engage in what Kuhn calls "normal science". That belief allows scientists to skip discussing the fundamentals and get right down to details.

Kuhn then likens normal science to puzzle solving. Like any normal puzzle there are rules and an expected and assured outcome under the prevailing paradigm. To solve a puzzle is testimony to the scientists ingenuity and is rewarded by peer recognition and status under normal science. To fail at a puzzle is not attributed to the puzzle or the rules but to the scientist. If he steps beyond the bounds of the paradigm for a solution his peers will not reward but ignore him, however right he may prove to have been in the future. The reward for a scientist thus follows not from finding truth in any objective sense of the word.
Normal science generates fundamental knowledge. To quote Kuhn (1971): "Normal science, the puzzle solving activity we have just examined, is a highly cumulative enterprise, eminently successful in its aim, the steady extension of the scope and precision of scientific knowledge" p. 52. But even as the paradigm allows for normal science to emerge, it thereby plants the seeds for its own demise. Under normal science, scientists seek and find facts to generalize, articulate and refine the core theories of the paradigm. In doing so, they encounter two types of results. Of course they find anticipated results that strengthen the incumbent paradigm and which do not call for theoretical revisions and refinements. The unanticipated ones are initially regarded as failures of the scientist or his instruments, not of the paradigm. But if persistent they require further scrutiny and possibly refinement of the core theories and if the unanticipated result resists this absorption it becomes an anomaly.

Initially such anomalies can be ignored by the mainstream but as they accumulate the paradigm faces a crisis. When confronted with a crisis, the rules of the incumbent paradigm are stretched, speculative new theories are formulated and discarded and the paradigm is pushed to its limits to exactly pinpoint where it fails. During the crisis more than one alternative paradigm may emerge and compete for dominance for a while. In those episodes a lot of energy is "wasted" on debating fundamentals and justifying one's choice of paradigm. Normal progress stalls. Kuhn stresses that such a conflict of paradigms cannot be resolved by anything other than the power of persuasion and the crisis ends only when most scientists are persuaded to adopt a new paradigm. Those who refuse to follow the mainstream are not necessarily wrong but will henceforth be ignored and regarded as either old fashioned, irrelevant and wrong.

Obviously there is a lot of resistance to paradigm change as vested interests, reputations and research programs have been built on the incumbent one. This, and the sudden resolution of paradigm conflicts, explains the revolutionary and pervasive effect of an occasional paradigm shift when it does occur. A revolution, although upsetting, ultimately means progress. Scientists 
cannot be convinced to abandon the incumbent paradigm if the new one does not at least promise to explain a considerable part of what was known under the old paradigm and some anomalies in addition. In that sense the new paradigm must be judged "better" before it will be adopted by the entire scientific community and progress is ensured.

The first task set to the scientists who adopt a new paradigm is to reformulate all data, theory and knowledge previously accumulated into the structure of the new paradigm. Measurements are aimed at verifying the new paradigm and well known phenomena must be recast in the light of new theories. A lot of this has been done in the persuasion battle for scientists' allegiance, but still much remains to be done. This activity is necessary to establish a new paradigm but is very unproductive in terms of generating new commercial opportunities. Arguably Newton's fundamentally new understanding of the pendulum-motion caused a revolution in physics but not in clock making. In this stage it is the absorption of old anomalies that does allow for increases in commercial opportunities. But as normal science is re-established the rate of opportunity creation quickly picks up.

Kuhn thus describes how and why fundamental scientific knowledge starts to progress at a significant rate but in a cyclical fashion after the establishment of its first paradigm. So far the theory was largely descriptive. But when we shortly consider the institutional setting in which scientists find themselves, the behavior that generates the above dynamics in fundamental knowledge creation can be explained, also in economic terms.

Kuhn stresses the importance of a relatively closed and intensively communicating scientific community that has the resources to finance its activities and can decide on how to allocate those resources relatively autonomously. This implies that the scientists decide among themselves what is and what is not science, what will and will not be financed and who is and who is not recognized as a fellow scientist. This makes reputation and peer recognition, not commercial application and expected rents, the key motivations for scientific activity. A reputation is built by establishing priority over discoveries.
Stephan (1996) refers to Merton (1957, 1968, 1969) who argued that scientists aim to establish priority of discovery by being the first to publish their findings in a recognized publication. Scientist do not seek to appropriate the rents of their knowledge, but actually get rewarded by giving up such exclusive ownership. Scientists are thus in the business of creating and publishing fundamental knowledge, not commercializing possible applications.

But because reputation does not pay the bills, the scientist will only seek peer recognition as long as the institutional setting ensures that income and prestige follow from it. ${ }^{18}$ Dasgupta and David's (1994) "new" economics of science considers these institutions to be endogenous and in this field game theory, principal-agent and incomplete contract theory have been used to establish that such endogenous institutions indeed translate reputation into wages, job opportunities, tenure and fringe benefits. ${ }^{19}$ The institutional structure may differ in the details between countries and institutions but its key attributes characterize a more or less global scientific community.

The institutional structure thus supports a self-governing community of scientists that generates a flow of fundamental knowledge in the pursuit of reputation. The question then arises how the scientific community can switch paradigms when all individual scientists have no incentive to do so as their reputations are built on the incumbent paradigm. One could think of this process as a rational speculative attack as for example modeled in Krugman (1979). In that model the gradual erosion of monetary reserves causes a sudden speculative attack prior to the actual depletion of reserves. The fundamental force that weakens an incumbent paradigm when all scientists are engaged in normal science was described above. As anomalies accumulate a crisis becomes ever more likely, making it less and less attractive to invest heavily in the incumbent paradigm and more attractive to engage in looking for a new paradigm. The rewards to the latter in terms of reputation and satisfaction increase and become less insecure whereas the puzzles of the incumbent paradigm become harder to solve and less likely to yield rewards in the future. 
Institutions that are built upon reputation therefore also explain the fact that young scientists, who have no reputation, are the first to switch and usually become the leading scientists in the next paradigm. To be among those leading scientists means to enjoy a high status indeed, as the rewards in science are distributed extremely unequally. The winners take most; the rewards for second place are marginal. About $6 \%$ of all publishing scientists produce $50 \%$ of all publications and consequently lead the citations indices and collect all prizes. ${ }^{20}$ What remains for the remaining $94 \%$ of publishing scientists is the gratification of solving an occasional puzzle and usually spending a lot of time trying to keep up and, although certainly not unimportant, training the next generation of scientists.

One final issue now remains to be addressed. ${ }^{21}$ If all scientific activity takes place in such institutional settings and paradigms occasionally shift, does that imply that the aggregate rate of fundamental knowledge creation follows cyclical dynamics? Paradigm shifts are sometimes pervasive and ripple throughout science and sometimes they are very much limited to a very specific field or discipline. Likewise the commercial opportunities that arise may sometimes be concentrated in a very narrowly defined industry and sometimes constitute a GPT. As these waves emerge to some extent independently and arrive randomly, they may cancel each other out across disciplines and generate at the aggregate level a smooth inflow of opportunities across industries.

By the same token, however, the waves may also strengthen each other, converge and cause a tsunami. In the model below I consider science to be one-dimensional and do not consider multiple disciplines or industries of application. This implies that all paradigm shifts cause waves that affect the opportunities for entrepreneurs and consequently reach the rate of innovation undiluted. One should therefore consider the model to be a description of the dynamics in a single innovation column where the interaction between one industry of application and one scientific discipline is analyzed or alternatively, consider it to describe General Purpose Technology (ICT, genetics) enabling paradigm shifts (solid-state physics, bio-chemistry and molecular biology) that affect some key scientific disciplines simultaneously.

\section{A model of knowledge based opportunity driven entrepreneurial growth}

Macro-economic models of growth have always aimed to explain the long run upward trend in GDP per capita by aiming for a constant long run growth rate. As a result these models abstract from the concept of economic cycles and concentrate on the accumulative types of knowledge generation that may support such a constant growth rate. As was mentioned above, instrumental knowledge accumulates smoothly. Arrow (1962) already realized that learning by doing could be a powerful engine of economic growth. New growth theory now builds on that basic principle by considering for example learning by learning (Lucas, 1988), learning by inventing (Romer, 1990; Grossman and Helpman, 1991) and building on previously attained quality levels (Aghion and Howitt, 1992). In new growth models new knowledge is usually created by building on what has been discovered in the past. This is reflected well in the specification of the innovation function. That function describes the (aggregate) relation between $R \& D$ inputs, usually labor, and the number of innovations produced each period. In a standard variety expansion model such as Romer (1990) and Grossman and Helpman (1991) that function has the general form:

$$
\dot{n}=n f(R)
$$

where $n$ is the stock of innovations, the range of goods or intermediates in production. A dot over the variable signifies the time derivative and $f(R)$ is a function of $R$ the amount of R\&D inputs. It is useful at this point to interpret $R$ as applied or entrepreneurial R\&D that seeks to develop new products or intermediates. The stock of innovations then equals the range of products or intermediates and expands at a constant rate in steady state equilibrium (where $R$ is constant). If utility or final goods production is assumed to exhibit a love for variety, then this translates into a constant growth rate for the economy. Note 
that $n$ appears on the right hand side to reflect a knowledge spillover from the past. Innovations made in the past make the generation of new innovations (proportionately) easier.

Such a set-up may capture the role of accumulative instrumental knowledge but ignores the cyclical nature of fundamental knowledge evolution. In addition it fails to capture the empirically well-established short and long-term cycles in economic growth. Note also, that the innovation function is assumed to exhibit constant returns, whereas there are in fact strong diminishing returns to re-combinatory instrumental knowledge generation.

A model that focuses on fundamental knowledge evolution may well do better in these respects. In addition it was already argued above that fundamental knowledge becomes ever more important in generating entrepreneurial opportunities. Therefore the model suggested below will include a scientific community. Its role will be to provide the raw material or "opportunities" for the entrepreneurial R\&D in equation (1). Assume:

$$
\dot{n}=\left(n^{\mathrm{P}}-n\right) f(R)
$$

where $n^{\mathrm{P}}$ is the stock of potential innovations or "opportunities" provided by scientists. ${ }^{22}$ As the stock of innovations cannot exhaust the stock of potential ideas, entrepreneurial $R \& D$ will run into strong diminishing returns as the number of realized ideas, $n$, approaches the number of potential ideas, $n^{\mathrm{P}}$. On the other hand, as the number of potential ideas expands relative to those realized, entrepreneurial activity becomes more effective per unit of R\&D labor and therefore more attractive. For now I assume this to be a linear relationship for simplicity. The idea that basic science provides the raw material for applied, entrepreneurial science is not new, but it is, to my knowledge, new to growth theory. "Downstream" the model can follow the standard set-up of an innovation driven endogenous growth model as was described in for example Grossman and Helpman (1991). Imperfect competition implies that rents reward successful entrepreneurs and this explains why they can and will borrow to finance innovative investments. It should be noted that the entrepreneurs exhaust and fully appropriate the rents, leaving none to motivate scientists. The more interesting challenges therefore lie in modeling the evolution of $n^{\mathrm{P}}$ as the outcome of the activities in the scientific community.

To do so I will first introduce some notation. Assume that an exogenously given number of people, $S^{*}$, engages in scientific activities. As was argued above they are driven by an internal motivation to solve the puzzles set by a paradigm and an external motivation to seek priority and peer recognition for their ideas. Output hence comes in the form of ideas and yields utility to the extent that curiosity is satisfied and peer recognition gained. We could capture the motivations in a utility function for scientists and assume that they maximize it by optimally choosing to engage in scientific activities. This would endogenize the number of scientists but when ideas and scientists are assumed to be homogenous and only one type of output is allowed then that maximization problem is trivial and we will not pursue it here. Instead all scientists, $S^{*}$ are simply assumed to engage in science. We now need to specify how they produce fundamental knowledge under the regime of normal and crisis-science.

\section{Normal science}

Consider the value of doing normal science to the individual scientist. Under normal science the scientist can choose one of the puzzles set by the paradigm. His output is then either an anticipated solution or unanticipated anomaly. Given the scientist's strong incentive to publish, I assume that the former adds one unit to the existing stock of knowledge, $K_{t}$, immediately. The latter adds to the stock of anomalies, $A_{t}$. To capture this process it is convenient to assume that all normal scientific activity generates anomalies as an unintended side-product. This implies that for the individual scientist:

$$
\begin{aligned}
& \dot{K}_{i t}=\left(K_{t}-K_{0}^{I}\right)^{-\alpha} f\left(S_{i t}\right) \\
& \dot{A}_{i t}=\left(K_{t}-K_{0}^{I}\right)^{\beta} f\left(S_{i t}\right)
\end{aligned}
$$

where $K_{0}^{\mathrm{I}}$ is the level of useful knowledge at the adoption of the incumbent paradigm and 
function $f$ exhibits the usual properties, $f(0)=0, f^{\prime}()>$.0 and $f^{\prime \prime}()<$.0 . In addition $f($. is normalized such that $f(1)=1$. By assuming $\alpha>0$ and $\beta>1$ we ensure that, as the paradigm ages, anomalies will accumulate faster than knowledge for a given level of scientific activity. Under normal science only anticipated outcomes are valuable as anomalies are ignored by peers. The value of being engaged in normal science is then simply equal to the number of anticipated solutions times the utility value of one anticipated solution denoted by $U^{N}{ }_{i t}$. We obtain:

$$
V_{t}^{N}=\dot{K}_{t} U_{t}^{N}
$$

where subscript $i$ can be dropped when all scientist are assumed to be identical. The value of an anticipated solution in turn is equal to the probability of obtaining priority for it, $P_{t}$, times the value attached to peer recognition, which we can normalize to equal 1 . One might add some constant to reflect the gratification of solving the puzzle, although I know from experience that this gratification is heavily eroded by the knowledge that someone else beat you to it. For now I therefore include it in the normalized value of peer recognition. ${ }^{24}$

Finally it should be noted that reputations are a lasting asset but when built under a paradigm, they loose their value once the paradigm shifts. As the reputation of a scientist consists of accumulated anticipated solutions under the paradigm we can model this by assuming that the scientist discounts the value of solutions under the current paradigm by the flow probability that the paradigm will shift, denoted by $\theta$. This probability is positively related to the number of accumulated anomalies and will be specified in the next section. We obtain for $V^{N}{ }_{t}$ :

$$
U_{t}^{N}=P_{t} \int_{t}^{\infty} e^{-\theta(\tau) \tau} d \tau
$$

$U^{N}{ }_{t}$ essentially is the marginal utility value of reputation that is created by the priority establishing publication of one paradigm-specific anticipated solution at time $t$. Assuming the individual scientist does not take into consideration his own impact on the stock of anomalies (i.e. he expects it to be 0 ex ante, $d A_{t} / d S_{i t}=0$ ) and the probability of getting published is exogenous to the individual scientist, reduces the problem to a simple maximization of (4) with respect to $S_{i t}$ given the first equation in (3). The aggregate flow of anomalies then follows from aggregating the second equation in (3) over all $i$.

When the paradigm is young, marginal productivity is high and as the probability of paradigm switches is low, $U^{N}{ }_{t}$ is high. As the flow of anomalies increases in the level of $K_{t}$ for any constant level of $S$, however, it can easily be verified that normal scientific activity will eventually fall as marginal productivity drops as will $U^{N}{ }_{t}$. This implies normal science cannot be a steady state and occasional paradigm shifts are required.

\section{Crisis science}

The steady accumulation of anomalies under normal science will inevitably provoke a crisis in the current paradigm. When a paradigm crisis arises, the scientific community abandons normal science and instead alternative paradigms are formulated, proposed and advocated. In the search for alternative paradigms the goal is not to solve puzzles under the incumbent paradigm. The focus shifts towards the limitations of the incumbent paradigm and therefore scientists only produce anomalies. In addition the quest at any point in time may yield theory that can serve as an alternative paradigm. To introduce the randomness of the length of the scientific crisis I assume:

$$
\begin{aligned}
& \dot{K}_{t}=0 \\
& \dot{A}_{t}=\left(K_{t}-K_{0}^{I}\right)^{\beta} f\left(S_{i t}\right) \\
& \operatorname{Pr}\left(P_{t}^{A}\right)=\varphi\left(A_{t}\right)
\end{aligned}
$$

where obviously we assume $\varphi^{\prime}\left(A_{t}\right)>0$. Note that because $K$ seizes to grow the number of new anomalies per unit of time will be constant. The third equation captures the assumption that as the number of anomalies increases so does the flow probability of an alternative paradigm arising at time $t$. This assumption ensures the crisis ends in finite time as long as there is scientific activity. 
When an alternative paradigm is formulated the aim is to get it adopted. As only one paradigm can be adopted, alternative paradigm formulation has the characteristics of a patent race or tournament in which the winner takes all. In addition the reward is enormous, both in reputation and intrinsic rewards. But the risks are high and the losers are usually doomed to insignificance as they stake their scientific reputation on a paradigm that is not accepted. At this point, however, it is hard to model the complete game among scientists and the battle for prevalence explicitly. Rather I will assume that the outcome of this battle of ideas is the emergence of a new paradigm that allows the scientific community to return to normal science with a new initial knowledge parameter.

$$
K_{0}^{A} \equiv \zeta K_{t}+\xi A_{t}
$$

where $K_{0}^{A}$ represents the useful knowledge base that alternative paradigm $A$ promises at adoption, i.e. the number of problems it can explain. The assumption that $0<\zeta<1$ implies that some of the knowledge under the incumbent paradigm must be sacrificed. $0<\xi<1$ implies an alternative cannot explain all anomalies. To be adopted a paradigm must be convincing to the scientific community at large. This implies that an acceptable alternative must at least explain some anomalies. The reason is that the alternative paradigm cannot be inclusive of the old paradigm by definition (see Kuhn, 1971). If that is the case some knowledge must be sacrificed when a new paradigm is adopted and the alternative can only be convincing if there are sufficient anomalies it can explain to compensate for that loss. Therefore there is a trade-off between parameters $\zeta$ and $\xi$. Only the incumbent paradigm can explain all current knowledge, such that setting $\zeta=1$ implies $\xi=0$ by the definition of an anomaly. A trade-off like:

$$
\xi=\frac{S_{t}(1-\zeta)^{\gamma}}{1+S_{t}(1-\zeta)^{\gamma}}
$$

would have the desired properties if $\gamma>1$ is assumed. Note that $\xi$ can only approach 1 from below as the number of scientists goes to infinity. Out of the known problems facing science, $K_{t}+A_{t}$, an alternative must now explain a larger share than the incumbent paradigm. The condition for paradigm switching is therefore:

$$
\frac{K_{0}^{A}}{K_{t}+A_{t}}>\frac{K_{t}}{K_{t}+A_{t}}
$$

Now consider that every period the scientific community is in crisis, there is a positive and increasing probability that an alternative paradigm is proposed. If at that point it satisfies (9) it will be accepted and the crisis ends. In future work the process may be adjusted to include endogenization or randomization of parameters. Still the current set-up already captures the natural assumption that a higher share of anomalies in the number of problems will increase the attractiveness of alternative paradigms.

The flow probability of paradigm switching, $\theta(t)=\varphi\left(A_{t}\right) * \operatorname{Pr}\left(K_{0}^{A}>K_{t}\right)$, is now equal to the probability that a convincing alternative that satisfies (9) is proposed and drawn at time $t$. At the resolution of the crisis the scientific community returns to normal science but starting from $(1-\xi) A_{t}$ anomalies and a new incumbent initial knowledge level $K_{0}^{I}=\xi A_{t}+\zeta K_{t}>K_{t}$. Now consider the resulting dynamics.

\section{The structure of scientific (R)evolutions}

Figure 1 illustrates how the key variables in the model evolve over time. The figure shows the evolution of the key state variables $K_{t}$ and $A_{t}$ over three cycles. Initially, under paradigm I knowledge, $K$ grows at a decreasing rate whereas the number of anomalies grows at an increasing rate according to equation (3). As $A$ rises, so does the probability of a crisis. When it emerges (grey area) the accumulation of knowledge stops while anomalies continue to increase in a linear fashion. As anomalies accumulate the probability of accepting a new paradigm increases. The length of the crisis is, however, a random variable.

At the end of the crisis paradigm II is accepted. Knowledge starts to grow from a new, higher level of initial knowledge. To reach that 


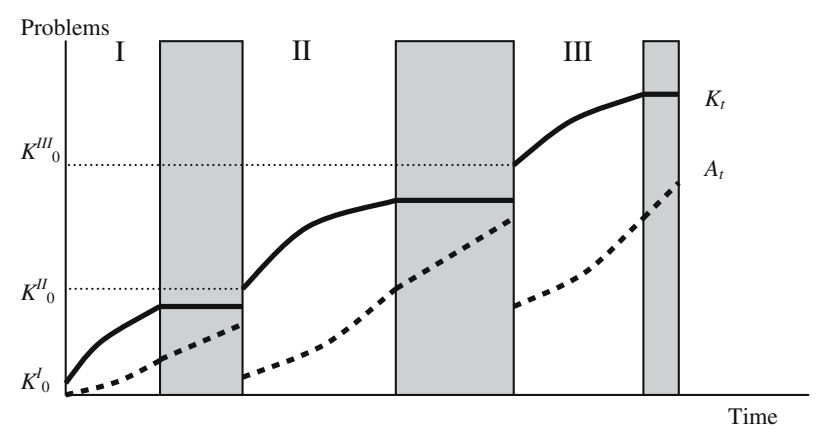

Figure 1. The evolution of the state variables over time.

higher initial level a number of open anomalies must be incorporated, which causes the number of anomalies to fall. Once more the number of anomalies starts to grow at increasing and the knowledge stock starts to expand at a decreasing rate, until a new crisis emerges.

\section{From knowledge to opportunity to innovation to cyclical growth}

Now the crucial point in this paper is to see that entrepreneurship can use the knowledge, $K_{t}$, accumulated in science as their raw material for thinking up new products and services. Vision and entrepreneurial talent are required to formulate commercially viable ideas for products and services from this stock of fundamental knowledge. In that sense $K_{t}$ can be considered an input, together with entrepreneurial vision and effort, in the generation of potential new products $n^{\mathrm{P}} \cdot{ }^{25}$ As was argued above scientists are not primarily interested in or particularly talented for this activity.

$n^{\mathrm{P}}$ then constitutes the universe of opportunities for entrepreneurial R\&D. It is the entrepreneurs that seize such opportunities and bring them to the realm of commercial enterprise by organizing financial, legal and knowledge resources inside or outside existing firms. It is they, who are motivated by expected profit flows. New growth theory thus attributes to them the role of generating public fundamental knowledge underlying their product as an externality to their quest for rents. By distinguishing the role of science from the entrepreneur we gain an important insight. We cannot rely on such externalities to emerge automatically.

As it is likely that entrepreneurial activity is easier and more rewarding when there is a large fundamental knowledge base, this model predicts, given the dynamics of scientific evolution, that in a paradigmatic crisis entrepreneurial activity stalls. The entrepreneurs are less successful in generating and realizing new ideas and therefore more likely to engage in other activities. Commercial R\&D activity would reallocate towards productivity enhancement in incumbent firms.

Similarly a breakthrough in science causes a jump in $K$ followed by relatively steep increases in the early stages of paradigm exploration. This boom in fundamental knowledge will, ceteris paribus, increase the number of opportunities and therefore attract more entrepreneurial activity, reallocating commercial $\mathrm{R} \& \mathrm{D}$ towards new product development. These cycles in knowledge evolution that cause cycles in entrepreneurial activity are therefore likely to translate into cycles in economic growth, cycles in R\&D activity and ultimately even in cycles in the labor market at large. ${ }^{26}$

\section{Concluding remarks}

The model presented in this paper seeks to uncover the interplay between scientific knowledge creation, entrepreneurial knowledge commercialization and innovation driven economic growth. It brings together insights from endogenous growth theory, entrepreneurship research and the philosophy of science to build a model around three key assumptions. I assume (with 
modern growth theory) that innovation, the commercialization of new knowledge, creates growth. Then (with entrepreneurship research) that entrepreneurs commercialize the opportunities that new knowledge creation presents, taking away the rents and profits as their reward. And finally (with the philosophy and economics of science) that knowledge creation follows a reputation driven, cyclical paradigm shifting dynamic process as described first by Kuhn (1971). The model generated opportunity driven cycles in entrepreneurial activity, waves of innovation and consequently transmits cycles in knowledge creation to economic growth. If one accepts the assumptions made, the implications of these findings could be profound.

First the realization that economic growth is a process that can be frustrated at every stage has some interesting policy implications. Seen in this light, the European Paradox of having plenty of good science but no growth to show for it, is not a paradox but simply a lack of entrepreneurial activity. Similarly the success of the US can be attributed to a well-balanced system of high quality scientific research and a vibrant entrepreneurial culture, and one wonders if the current trend towards mixing these functions is a good idea. The model also has implications for less developed and developing countries. Growth may start by helping local entrepreneurs to recognize and exploit the opportunities in slightly more developed economies. But then high growth in China and India can thus be predicted to stall once the opportunity frontier, freely available in the advanced economies, is reached. Additionally until that time they would be crazy indeed to respect intellectual property rights. The recipe for sustainable long run growth is to build a scientific community that can tap into but also contributes to the global fundamental knowledge pool and to make sure the opportunities that emerge continue to be implemented.

The paper could also shed light on some long standing issues in the academic literature. The touched upon importance of scientific institutions combined with the establishment of the first universities in Europe in the late 15th century may help explain the fundamental question in economic history: "Why Europe, why in the 17th century?'. Connecting Kuhn's historical approach to science and mainstream endogenous growth models could also to begin to bridge the gap between evolutionary and rational choice based theories of economic growth. This paper does not address these issues in great detail, but taking an integrated approach to growth creates ample opportunities for an entrepreneurial scientist to pursue in the future.

\section{Acknowledgement}

This paper was prepared for the workshop on "The Nature of Opportunity", held in March 2005 at the Max Planck Institute for Economics in Jena, Germany.

\section{Notes}

1 Kuznets (1971) in his Nobel speech for example mentions it. Landes (1969) also linked scientific discovery to economic growth as did and do many.

2 See Audretsch and Thurik (2001c) and Karlsson et al. (2004) for overviews of the literature that make this point compellingly. Recent references listed there include among others Acs (1996, 1999), Acs and Audretsch (2001), Audretsch and Thurik (1997, 2001a, 2001b), Audretsch et al. (2002), Carree and Thurik (1998), Carree et al. (1999, 2002), Thurik (1996), Verheul et al. (2003), who frequently go all the way back to early writers as Schumpeter (1934) and Knight (1921).

3 Although it is hard to get any group of entrepreneurship researchers to agree on a definition of their field, this definition as well as many others contains the key concept of a commercial opportunity that either exists objectively or is perceived subjectively by the entrepreneur and is the prerequisite for the entrepreneur to act.

4 This argument has been made much more elaborately in Acs et al. (2004).

5 This explanation in terms of the production possibilities curve is due to Landström (1999).

6 Hébert and Link (1989) provide an extensive survey of the field.

7 Lucas (1988) should also be mentioned as one of the founding fathers of endogenous growth theory. His model, however, relies on the accumulation of productive skills in the labour force rather than explicitly model innovation in products and services. As there is no role for the entrepreneur in that class of models it is less interesting to the purpose of this paper.

8 One should not confuse these terms with Lyotard's (1979) terminology, where "instrumental knowledge" is in fact scientific and opposed to "narrative knowledge". My terminology is closer to the use in cognitive psychology (e.g. Dickinson and Shanks, 1995), where "instrumental 
knowledge" is the knowledge of cause and effect relations. I closely follow the distinction proposed by Jantsch (1967) between intrinsic and instrumental knowledge and the OECD's general understanding of the terms.

9 Commercial R\&D emerged in the early 20 th century as scientific methods of systematically looking for fundamental knowledge were applied in the quest for commercial applications as well.

10 Much like learning-by-doing generates fundamental understanding by accident. But the assumption that science aims for fundamental knowledge should not be read as a claim that real life scientists do not care for commercial applications. Some or even many scientists may try to turn their own fundamental knowledge into opportunities and products by starting up a business, however, in my definitions they then seize to be pure scientists as they become entrepreneurs and later on producers.

11 Brandstetter and Ogura (2005) for example document an explosion in patents citing academic science since the mid $80 \mathrm{~s}$. The fact that scientists and universities are engaged in the commercialization of their knowledge could also explain the increasing occurrence of scientific citations in patents. In fact the 1980 Baht-Dole Act was intended and has been successful in stimulating such commercialization efforts in the US and many such initiatives have been launched around the world. The model I present here makes a strict separation in functions, but does intend to claim that people or institutions are limited to just one of both activities. Empirically the boundaries between the pure scientific pursuit of knowledge and the commercial R\&D process can hardly be drawn and have been blurred throughout history. James Watt was an engineer in the service of mining corporations. And Boyl's scientific work on the properties of gases undeniably helped improve the original design of the steam engine as much as the many engineering problems that arose have inspired new scientific discoveries and commercial opportunities. This mixing of functions does not, however, imply that a model that is built on "pure" types has no merit.

12 For learning-by-doing this is obvious as one learns from observing already applied ideas. In Romerian innovation driven growth models the assumption is that new innovations are somehow easier to create when more innovations have been made in the past. This intertemporal knowledge spillover clearly intends to capture the productivity of old ideas in creating new ones.

13 Economic growth, measured as the expansion of GDP, is well known to miss in particular the contribution of radically new goods and services in the early stages of their life cycle. The famous quote from Solow that: "computers are everywhere but in the productivity statistics", spawned a literature on the productivity paradox that also explores these measurement problems. By today computers undeniably show up in GDP and their massive impact is picked up in productivity statistics. Re-combination of ICT knowledge with existing knowledge on logistics, information management, engineering, etc. etc. etc. make this technology be felt much more than the original introduction of personal computers no-one knew how to put to good use.
14 Jaffe (1989) and Branstetter and Ogura (2005) point out that scientific knowledge plays an increasing role in patents, particularly in emerging General Purpose Technologies such as biotech and ICT.

15 The earlier mentioned papers by Olsson (2000, 2005) are two of the rare instances to my knowledge, where knowledge creation is probed at the micro-level to inform growth theory. In another paper, Olsson and Frey (2002) the entrepreneur is explicitly given the role of recombining existing ideas into new commercial products. Olsson stresses the importance of occasional Kuhnian paradigm shifts for long run growth in all these papers and also predicts technology driven long Kondratieff cycles in growth. In his models, however, he does not explicitly consider the institutional peculiarities in basic science that generate such dynamics nor does he recognize the function of anomalies in endogenously provoking a paradigm shifts (see below). In addition his elegant conceptualization of knowledge in a multidimensional idea space adds more complexity that I require to make the point of this paper.

16 In this paper I consider the overview articles by Stephan (1996) and Dasgupta and David (1994) as representative for the mainstream in this field and used Diamond (2006) for more recent references.

17 The philosophy of science has moved from the simple linear accumulation view to Popper's (1968) falsification theory that Lakatos (1971) and Kuhn (1971) sought to improve. Lakatos' and Kuhn's historical approaches were then refined into the more social-constructivist (Bijker, 1995) and actor-network (Latour, 1987) theories. These modern theories, however, bring in a lot of complexity that I would have to abstract from in the model to keep it manageable.

18 Stigler and Becker (1977) for example argued all humans have the same utility function and scientist are no different than humans in that respect.

19 Diamond (1986) for example estimated the monetary value of a citation in annual additional earnings between 50 and 1,300 dollars. Cole and Cole (1967, 1973), Gaston (1970) and Cole (1978) also provide evidence that scientific reward systems are fundamentally different and succeed in aligning individual incentives with the Mertonian (1969) ideal of a universalistic scientific community that would discover and disclose knowledge quickly.

20 See Stephan (1996).

21 I thank an anonymous referee for making this point.

22 To be precise, the scientists do not develop off the shelve opportunities but rather develop knowledge that visionary entrepreneurs can use to formulate product ideas. One might therefore wish to put some opportunity/idea production function between $n^{\mathrm{P}}$, the opportunities and raw knowledge, the output of scientific activities, $K$. Entrepreneurial talent and effort may then be considered inputs in this production function as well, e.g. $n^{\mathrm{P}}=f(K, E, \ldots)$. As long as this function is homogenous of degree 1 with respect to $K$, the stock of knowledge, this will not change the results.

${ }^{23}$ A nice quote by Charles Stine, advocating basic research in a presentation to DuPont's Executives in 1926, 
shows that managers have realized the importance of science for growth early in the last century. He was quoted in Stephan (1996) to have said: "applied research is facing a shortage of its raw materials", p. 1209. Perhaps an instance of instrumental knowledge in economics.

24 Note that, for simplicity, I assume that all anticipated solutions add similarly to reputation. Of course in reality puzzles under the paradigm differ greatly in status.

25 See Keilbach and Sanders (2006).

26 See for example Sanders (2005) and Acemoglu (2006) on models that relate technical change to labor market implications for low and high skilled.

\section{References}

Acemoglu, D., 2006, 'Equilibrium Bias of Technology', NBER Working Papers, No. 11845, NBER, Cambridge MA.

Acs, Z., 1996, Small Firms in Economic Growth, in Z. B. Acs Carlsson and R. Thurik (ed). Small Business in the Modern Economy, Oxford: Blackwell Publishers1-62.

Acs, Z., 1999, The New American Evolution, in Z. Acs (ed). Are Small Firms Important? Their Role and Impact, Dortrecht: Kluwer Academic Publishers1-20.

Acs, Z. and D. Audretsch, 2001, The Emergence of the Entrepreneurial Society, Stockholm: Swedisch Foundation for Small Business Research.

Acs, Z., D. Audretsch, P. Braunerhjelm and B. Carlsson, 2004, 'The Missing Link: the Knowledge Filter and Entrepreneurship in Economic Growth', CEPR-discussion papers, No. 4783 Stockholm, www.cepr.org/pubs/dps/DP4783.asp.

Acs, Z., D. Audretsch, P. Braunerhjelm and B. Carlsson, 2006, 'Growth and Entrepreneurship: an Empirical Assesment', CEPR-discussion papers, No. 5409 Stockholm, www.cepr.org/pubs/dps/DP5409.asp.

Aghion, P. and P. Howitt, 1992, 'A Model of Growth through Creative Destruction', Econometrica 60, 323-351.

Aghion, P. and P. Howitt, 1998, Endogenous Growth Theory, Cambridge MA: MIT Press.

Arrow, K., 1962, 'The Economic Implications of Learning by Doing', Review of Economic Studies 29, 155-173.

Audretsch, D. and M. Keilbach, 2005, 'Entrepreneurship, Growth and Restructuring', Max Planck Institute of Economics Discussion Paper Series, No. 1306, Max Planck Institute, Jena.

Audretsch, D. and R. Thurik, 1997, 'Sources of Growth: The Entrepreneurial vs the Managed Economy', in: Tinbergen Institute Discussion Papers, No. 97-109/3, Tinbergen Institute, Amsterdam.

Audretsch, D. and R. Thurik, 2001a, 'What is New about the New Economy: Sources of Growth in the Managed and Entrepreneurial Economy', Industrial and Corporate Change 10, 267-315.

Audretsch, D. and R. Thurik, 2001b, Capitalism and Democracy in the 21st Century: from the Managed to the Entrepreneurial Economy, in D U. Mueller Cantner (ed). Capitalism and Democracy in the 21st Century, Heidelberg: Physica-Verlag.
Audretsch, D. and R. Thurik, 2001c, 'Linking Entrepreneurship to Growth', OECD STI Working Paper Series, 2001/2, Paris.

Audretsch, D. and R. Thurik, 2002, 'Linking Entrepreneurship to Growth', OECD STI Working Papers, OECD, Paris.

Audretsch, D. and M. A. R. Carree Stel Thurik, 2002, 'Impeded Industrial Restructuring: The Growth Penalty', Kyklos 55, 81-97.

Barro, R. and X. Sala-I-Martin, 2004, Economic Growth, 2nd ed, Cambridge MA: MIT-Press.

Bijker, W., 1995, Of Bicycles, Bakelites and Bulbs; Towards a Theory of Sociotechnical Change, Cambridge MA: MIT Press.

Brandstetter, L. and Y. Ogura, 2005, 'Is Academic research driving a Surge in Industrial Innovation? Evidence form Patent Citations', NBER Working Papers, No. 11561, NBER, Cambridge Massachussets.

Bresnahan, T. and M. Trajtenberg, 1995, 'General Purpose technologies- Engines of Growth?', Journal of Econometrics 65, 83-108.

Cantillion, R., 1755, 'The Circulation And Exchange Of Good And Merchandise', in M. Casson (ed.), (1990) Entrepreneurship, Cheltenham: Edward Elgar Publishers, 5-10.

Carree, M. and R. Thurik, 1998, 'Small Firms and Economic Growth in Europe', Atlantic Economic Journal 26, 137-146.

Carree, M., A. van Stel, R. Thurik and S. Wennekers, 1999, 'Business Ownership and economic Growth: An Empirical Investigation', EIM Research Report, No. 9809, EIM, Zoetermeer.

Carree, M. and A. R. S. Stel Thurik Wennekers, 2002, 'Economic Development and Business Ownership: An Analysis using Data of 23 OECD Countries in the Period 1976-1996, Small Business Economics 19, 271-290.

Cole, S. and J. R. Cole, 1967, 'Scientific Output and Recognition: A Study in the Operation of the Reward System in Science', American Sociological Review, 32, 377-390.

Cole, J. R. and S. Cole, (1973), Social Stratification in Science, Chicago: Chicago University Press.

Cole, S., 1978, 'Scientific Reward Systems: A Comparative Analysis', Research in Sociology of Knowledge, Sciences and Art, 1, 167-190.

Dasgupta, P. and P. David, 1994, 'Towards an New Economics of Science', Research Policy 23, 487-521.

Diamond, A., 1986, 'What is a Citation Worth?', The Journal of Human Resources 21, 200-215.

Diamond, A., 2006, Economics of Science, in S. Durlauf and L. Blume (ed). The New Palgrave Dictionary of Economics, 2nd Ed, London: Pagrave Publishers.

Dickinson, A. and D. Shanks, 1995, Instrumental Action and Causal Representation, in D. Sperber, D. Premack and A. Premack (ed). Causal Cognition, Oxford: Clarendon Press.

Dosi, G., 1982, 'Technological Paradigms and Technological Trajectories: A Suggested Interpretation of the Determinants and Directions of Technical Change', Research Policy 11, 147-162.

EU, 2003, Green Paper on Entrepreneurship in Europe, Commission of the European Communities, Brussels, downloadable at http://ec.europa.eu/enterprise/entrepreneurship/ green_paper/green_paper_final_en.pdf. 
EU, 2004, Action Plan; The European Agenda for Entrepreneurship, Commission of the European Communities, Brussels, downloadable at: http://ec.europa.eu/enterprise/ entrepreneurship/promoting_entrepreneurship/doc/com_70_en.pdf.

Gaston, J., 1970, 'The Reward System in British Science', American Sociological Review, 35, 718-730.

Griliches, Z., 1979, 'Issues in Assessing the Contribution of Research and development to Productivity Growth', Bell Journal of Economics 10, 92-116.

Griliches, Z., 1984, R\&D and Innovation: Some Empirical Findings; Comments, in Z. Griliches (ed). $R \& D$, Patents and Productivity, Chicago: University of Chicago Press.

Griliches, Z., 1992, 'The Search for R\&D Spillovers', Scandinavian Journal of Economics 94, S29-47.

Grossman, G. and E. Helpman, 1991, Innovation and Growth in the Global Economy, Cambridge, Massachusetts: MIT Press.

Hébert, R. and A. Link, 1989, 'In Search of the Meaning of Entrepreneurship', Small Business Economics 1, 39-49.

Jaffe, A., 1986, 'Technological Opportunity and Spillover of R\&D: Evidence from Firms'Patents, Profits and Market Value', American Economic Review 76, 984-1001.

Jaffe, A., 1989, 'Real Effects of Academic Research', American Economic Review 79, 957-970.

Jaffe, A. and M. Trajtenberg, 2002, Patents, Citations and Innovations; A Window on the Knowledge Economy, Cambridge, Massachusetts: MIT Press.

Jantsch, E., 1967, Technological Forecasting in Perspective, Paris: OECD

Jones, C., 2006, Growth and Ideas, in: P. Aghion (Ed.), Handbook of Economic Growth, Forthcoming Elsevier Publishers.

Karlsson, C., C. Friis and T. Paulsson, 2004, 'Relating Entrepreneurship to Economic Growth', CESIS Electronic Working Paper Series, No. 13.

Keilbach, M. and M. Sanders, 2006, 'Entrepreneurship in a Model of Economic Growth', Max Planck Institute of Economics Working Paper Series, forthcoming.

Kirzner, I., 1973, Competition and Entrepreneurship, Chicago: University of Chicago Press.

Knight, F., 1921, Risk, Uncertainty and Profit, New York: Houghton Mifflin.

Krugman, P., 1979, 'A Model of Innovation, Technology Transfer and the World Distribution of Income', Journal of Political Economy 87, 253-266.

Kuhn, T., 1971, The Structure of Scientific Revolutions, 3rd Ed. 1996, Chicago: The University of Chicago Press.

Kuznets, S., 1971, Modern Economic Growth: Findings and Reflections, Lecture to the memory of Alfred Nobel, delivered December 11th 1971, Stockholm, Sweden, downloaded from http://nobelprize.org/economics/laureates/1971/kuznets-lecture.htm.

Lakatos, I., 1971, 'History of Science and Its Rational reconstruction', Boston Studies in the Philosophy of Science 8, 91136.

Latour, B., 1987, Science in Action, translated in Dutch by de Lange and Maters [1988], Wetenschap in Actie, Amsterdam: Bert Bakker Uitgeverij.
Landes, D., 1969, The Unbound Prometheus: Technological Change and Industrial Development in Western Europe from 1750 to the Present, Cambridge: Cambridge University Press.

Lanström, H., 1999, 'Entreprenörskapets Rötter', Studentlitteratur, Lund.

Lucas, R., 1988, 'On the Mechanics of Economic Development', Journal of Monetary Economics 22, 3-42.

Lyotard, J., 1979, The Post-Modern Condition, Manchester University Press.

Merton, R., 1957, 'Priorities in Scientific Discovery: A Chapter in the Sociology of Science', American Sociological Review 22, 653-659.

Merton, R., 1968, 'The Matthew Effect in Science', Science 159, 56-63.

Merton, R., 1969, 'Behavior Patterns of Scientists', American Scientist 57, 1-23.

Nelson, R. and S. Winter, 1977, 'In Search of a Useful Theory of Innovation', Research Policy 6, 35-76.

Olsson, O., 2000, 'Knowledge as a Set in Idea Space: An Epistemological View on Growth', Journal of Economic Growth 5, 253-275.

Olsson, O., 2005, 'Technological Opportunity and Growth', Journal of Economic Growth 10, 35-57.

Olsson, O. and B. Frey, 2002, 'Entrepreneurship as Recombinant Growth', Small Business Economics 19, 69-80.

Popper, K., 1968, The Logic of Scientific Discovery, London: Hutchinson Publishers.

Romer, P., 1990, 'Endogenous Technical Change', Journal of Political Economy 98, S71-S102.

Sanders, M., 2005, Technology and the Decline of Unskilled Labour Demand: A Theoretical Analysis of the US and European Labour Markets, Cheltenham: Edward Elgar.

Schumpeter, J., 1934, 'The Theory of Economic Development', in: M. Casson (ed.) (1990) Entrepreneurship, Cheltenham: Edward Elgar Publishers, 105-134.

Segerstrom, P. and T. E. Anant Dinopoulos, 1990, 'A Schumpeterian Model of the Product Life Cycle', The American Economic Review 80, 1077-1091.

Shane, S. and S. Venkataraman, 2000, 'The Promise of Entrepreneurship as a Field of Research', Academy of Management Review 25, 217-221.

Solow, R., 1957, 'Technical Change and the Aggregate Production Function', Review of Economics and Statistics 39, 312-320.

Stephan, P., 1996, 'The Economics of Science', Journal of Economic Literature 34, 1199-1235.

Sterman, J., 1982, The Growth of Knowledge: Testing a Theory of Scientific Revolutions with a Formal Model, in MIT Working Paper, No. 1326-82, available online at: https:// hpds1.mit.edu/retrieve/1636/SWP-1326-09065900.pdf .

Sterman, J. and J. Wittenberg, 1999, 'Path Dependence, Competition and Succession in the Dynamics of Scientific Revolution', Organization Science 10, 322-341.

Stigler, G. J. and G. S. Becker, 1977, 'De Gustibus Non Est Disputandum', American Economic Review, 67, 76-90.

Thurik, R., 1996, Small Firms, Entrepreneurship and Economic Growth, in Z. B. Acs Carlsson and R. Thurik (ed). Small 
Business in the Modern Economy, Oxford: Basil Blackwell 126-152.

Verheul, I and S. D. R. Wennekers Audretsch Thurik, 2003, An Eclectic Theory of Entrepreneurship, in D. Audretsch (ed).
The Globalisation of the World Economy, Cheltenham: Edward Elgar Publishers.

Wennekers, S. and R. Thurik, 1999, 'Linking Entrepreneurship and Economic Growth, Small Business Economics 13, 27-55. 